\title{
The Expectant Brain and the Placebo Magic; Does it have a Survival Value?
}

\author{
Touraj Nayernouri, MD, FRCS ${ }^{1+}$ \\ ${ }^{1}$ Academy of Medical Sciences Islamic Republic of Iran, Tehran, Iran
}

\section{Introduction}

"The placebo effect is the reduction of a symptom or a change in a physiological parameter when an assumingly inert treatment (the placebo) is administered along with a complex set of psychological stimuli that tell the patient that a benefit may occur".

It is perhaps a century since the 'placebo' response has been clinically and scientifically investigated and established as a fact, although its magical powers have been used for millennia by 'witch doctors,' 'medicine men' and 'shamans' in a ritualistic manner to heal the sick by expelling the causative evil spirits from the afflicted.

The aim of this article is to delve into the evolutionary advantage and benefits of such a mechanism for the developing human societies and its persistence to the present day despite modern understanding of disease causation and the logic of evidence-based medicine.

We shall begin with a brief summary of clinical and experimental trials demonstrating the reality of the placebo and nocebo effects and the contributing factors including social and environmental as well as possible genetic influences, and then go on to examine some mechanisms, such as suggestibility and obedience and finally, the role of expectation in the magical effects of the placebo response.

In February 2020, the New England Journal of Medicine published a review article entitled 'Placebo and Nocebo Effects. ${ }^{2}$ In the introduction, the authors define these effects as the "effects of patients' positive and negative expectations, respectively, concerning their state of health" and they go on to state that "in many double-blind clinical trials....the response to placebo are similar to the response to active treatment, and up to $19 \%$ of adults and $26 \%$ of elderly persons taking placebo report side effects." They further describe some contributing factors as well as possible mechanisms of the placebo and nocebo effects which we shall consider later in this article.

\section{Clinical Studies}

The reality of the placebo effect has now been established beyond a reasonable doubt. Enck and Klosterhalfen have given a notable review of 'Placebos and the Placebo Effect in Drug Trials' in the Handbook of Experimental
Pharmacology in 2019.3 As they mention in their introduction, scientific placebo research started as early as the 1940s and was continued by Henry K. Beecher in 1955 and Steward Wolf in 1959 and published in Pharmacological Reviews.

We shall forgo describing the use of placebos in double blind placebo-controlled clinical trials of drug manufacturing as they have been described adequately in many articles and books.

Schedlowski et al have also reviewed the Neuro-BioBehavioral mechanisms of placebo and nocebo responses in Pharmacological Reviews, 2015 and they state that "The placebo effect itself, the symptom improvement after inert treatments in clinical trials...is mediated via three interdependent factors: patients' expectation about treatment benefits, the quality and quantity of doctorpatient communication, and associative (conditioning) learning processes." 4

After a detailed review of these mechanisms, they pose the question "why did placebo responses develop during evolution." and refer to two articles by T. Kaptchuk.

Although Kaptchuck has given an analysis of placebo studies and ritual theory in the Philosophical Transactions of the Royal Society in 2011, and has raised some interesting points with regard to ritual healing of the Navajo nation in the United States compared with acupuncture and biomedical healing, he does not address the evolutionary necessity of the placebo response. ${ }^{5} \mathrm{He}$ goes on to state that "Metaphors and symbols, the healer's prestige, social interactions with relatives and community members....all provide vehicles for and multi-dimensional guide posts to a process that is meant to transform a patient from brokenness to intactness."

It seems that the theatrics of ritual healing is akin to the catharsis experienced by the audience during tragic drama, but more potent, as the healer and the patient form a more intimate bond during the healing process.

\section{Neuro-physiological Studies}

Several studies have been performed to demonstrate quantifiable physiological changes in the brain during placebo administration, including neuronal activity, neuro-transmitter and hormonal release as well as imaging 
regional specific brain activity during such procedures. A few examples are described below to show the concomitant substrates of the placebo response.

1. Functional magnetic resonance (fMRI) Imaging was performed during acupuncture trials for pain.

Placebo (sham) acupuncture needles showed activation of the rostral anterior cingulate cortex as well as the right insula; areas which are involved in emotional modulation and the bridging of sensation with emotion; the patients reported decrease in subjective pain during the fMRI imaging. ${ }^{6}$

2. Fourteen healthy young men who received an injection of a painful substance in their jaw muscles reported a significant reduction of pain when receiving a normal saline drip intravenously, which was said to be a novel analgesic medication. Positron emission tomography of their brains showed increase activity in mu-opioid receptor binding in pain processing regions of their brain, including the cingulate, insula, caudate and amygdala. ${ }^{7}$

3. During stereotactical operation of the brain for Parkinson's disease, when the patient is conscious and able to respond, recordings of neuronal discharge rates of the subthalamic ganglia of the brain are recorded. The discharge rates of these neurons can be altered whether given apomorphine (which reduces rigidity and tremor in Parkinson patients) or a placebo. Prior to the operation, the patients were given apomorphine and the rigidity and tremor of their limbs was reduced. During the operation, while the activities of the subthalamic neurons were being recorded, the patients were told that they were being injected with apomorphine, whereas they were being injected with normal saline. Not only did the patients report the easing of their symptoms, but the firing rates of their basal ganglion cells were also reduced. In other words, the placebo in fact altered the activity of their brain cells. ${ }^{8}$

And so science has established the reality of the mental effects of the placebo response and scientific experiments have shown some of the correlates of this response.

\section{Mechanisms}

Suggestibility of the human psyche is perhaps the most important factor in the efficacy of the placebo effect. Although hypnosis is often given as a major example of suggestibility, the phenomenon is much more widespread in human behavior than hypnosis, which is only one manifestation of suggestibility. Advertising firms have taken advantage of this characteristic to impose their products and there were times when they used subliminal messages for a few milliseconds which did not register consciously, yet the message to buy this or that object had its subconscious effect.

A major influential consequence of suggestibility is observed during mass rallies by despotic rulers whose followers, in a trance-like state, believe and follow instructions in total abeyance of objective reasoning, duped by the polemics of their leaders; a consequence of the common herd instinct and behavioral mimicry. On a more mundane level, suggestibility exhibits itself in gossip with family members and friends and recently by social media, despite much incorrect information. Another facet of the phenomenon, however tangential it may be, is obedience to authority and performing tasks which the subject imagines are expected of him, no matter how heinous or immoral, they may seem.

Stanley Milgram conducted several experiments in the 1960 s to test this concept. He recruited subjects, designated as "teachers" who were told that the object of the experiment was to study the effects of punishment on learning ability. The teachers had to administer electric shocks of increasing severity, from 15 to 450 volts to the "learner" who was seated in another room unseen by the teacher, if he responded incorrectly to the questions that were asked. The "learner", however, was an actor and did not in fact receive any electric shock, but pretended with increasing degrees of painful responses, from a small grunt to agonizing screams, with increasing voltages. The experimenter was constantly pressing the teacher to increase the shocks, despite the learner's painful responses. Sixty-five percent of the teachers were willing to progress to increasing voltage levels despite the learners seeming agony. Only a minority disobeyed and challenged the authority of the experimenter. ${ }^{9}$ The object of mentioning these experiments is to stress the role of authority in influencing the obedience of the subject.

It is of course fashionable nowadays among social scientist to seek a genetic basis for all human behavioral traits, and no doubt genetic and epigenetic phenomena do have a role in the physical and psychological effects of the placebo response, and we shall discuss some recent studies relevant to the genetic basis of such behavior. And finally, perhaps the two most important concepts in the placebo magic are the 'doctor -patient' relationship and the patient's expectation to be healed.

The shaman or the modern doctor, paragons of authority in their ritualistic garbs and settings, horned animal skins or white gown, stethoscope and other paraphernalia, fill the patient with awe and respect. Mesmerized and with bated breath and heightened expectation, the patient awaits the prognostications of the authoritarian master. How the healer approaches his patient, how much attention he pays to his/her complaints with patience, and how concerned he seems, are paramount in the process of healing. These mechanisms have been shown to activate the brain reward systems and to release endogenous neurotransmitters and/or neurohormones that mimic the expected pharmacological effects. ${ }^{10,11}$

It is unfortunate, however, that in modern medical practice, the 'art' of medicine has been replaced by a cursory history taking and physical examination and reliance has been placed mainly on tests and imaging, however useful they are in diagnosis, yet they have eroded 
the trust of the patient in her/his physician.

In alternative medicine and especially in homeopathy, which have gained a resurgence of popularity recently, even though the medications prescribed are inert placebos, the ritual of detailed history taking and attention to life style, personality and family history, which in the first homeopathic consultation can last up to 2 hours, as well as the ritual of referring to the Homeopathic Materia Medica and the voluminous 'Repertories' to match the patients symptoms to a particular homeopathic diagnosis, works its magic. ${ }^{12,13}$

It is obvious that such phenomena as the placebo and nocebo effects cannot be taken lightly. We have described the weight of the clinical and experimental evidence to show their reality and some possible mechanisms by which they may act.

\section{Evolutionary Utility}

We must now conjecture its evolutionary significance and the survival value that it might confer. We have no solid evidence of the placebo effect in non-human mammals and apart from a few anecdotal homeopathic cures in veterinary practice, many of which may be a classical Pavlovian type conditioning, nothing can be surmised.

Silberman mentions the function of the 'pain face' among monkeys when in pain and vulnerable, as a social signal to summon aid, but the pain and the pain face seem to abate once reinforcements arrive, ${ }^{14}$ not unlike the tooth ache that often disappears once we visit the dentist.

And so, we must seek the evolutionary origins of the placebo effect within the genus Homo. There is no evidence that we can surmise from the fossil record, although we can postulate some evolutionary utility within the Homo sapiens species during the last glacial period and the upper paleolithic era (50000-12 000 years ago). Shamanistic and other rituals of purgation of discomfort, pain and disease, as seen in contemporary primitive hunter-gatherer societies have been mentioned, but such observations do not illuminate the origin of the effect and it is unwise to extrapolate in seeking its evolutionary utility by this approach.

Archeological records demonstrate distinctive signs of behavioral and cultural modernity associated with the anatomically modern Homo sapiens in southern Europe at this time. Contrary to popular opinion, they did not live in caves in the upper paleolithic period but used them as camp sites for brief periods of the year as they followed the movements of animal herds which they hunted and were probably aware of the seasonal migrations of their prey. They trapped their prey at watering holes or in deep ravines or forced the larger animals such as mammoths or rhinos over cliffs. Sometimes, these caves were used as gathering sites for tribal reunions and exchange of goods and news.

During the Aurignacian period (45000-35000 years $\mathrm{BP})$, there is evidence that small groups of Homo sapiens hunter-gatherers used a variety of body ornaments for social display, some of which were imported from distant sites, probably by exchange and barter between different groups travelling throughout southern Europe. The making and wearing of body ornaments may indicate the development of social stratification and making representational images can be construed as the development of complex conceptual mental frameworks. These developments required a means of communication which necessitated some form of language more sophisticated than previously. ${ }^{15}$

From about 35000 years BP onwards, there is evidence of organized settlements in campsites with storage pits. Artistic artifacts including cave paintings, carvings and engravings on bone or ivory, Venus figurines and musical instruments have been recovered and dated to this period. Instruments such as darts, harpoons, fish hooks as well as oil lamps, rope and eyed bone needles attest to significant cultural developments. There are remains of settlements and burial of the dead covered with red ocher and thousands of ivory beads as ornaments as well as weapons, as discovered in Sunghir in Russia. ${ }^{16}$ These burials are dated to between 29000- 24000 years BP.

Paleolithic cave paintings in southern France and Spain such as those in Chauvet (circa 35000 years BP), Lascaux (circa 17000 years BP) and Altamira (circa 15000 years BP) depicting magnificent colorful renditions of animals such as horses, wild reindeer (caribou), mammoths, bisons and rhinoceros which they hunted for food, stands in contrast to popular literature which associate these paintings with ritual and magic. ${ }^{17}$ Most of these cave paintings cover periods of millennia and are not homogenous as they contain many poor renditions and much graffiti, probably by adolescents.

After this brief archeological interlude, we must return to the possible conceptual mind sets of Homo sapiens at that time.

There have been suggestions of a modular structure of the brain and their functional connections which developed during the paleolithic era as a possible scientific model, ${ }^{18}$ but this model has been criticized recently by several researches who assign an important role to cultural evolution. Contrary to the idea of cognitive modularity put forward by evolutionary psychologists, these modules or traits did not appear suddenly and many were present in primates and early hominids but in primitive forms. ${ }^{19}$ If they buried their dead with their worldly goods and in a ritualistic manner, they most probably had a fear of death and a hope of afterlife.

Fear is probably one of the strongest emotions experienced by humans as well as most other 'higher' life forms. There are several aspects to this emotion besides that of death. Fear of predation, hunger, pain and illness, thunderstorms, floods, earthquakes and other natural catastrophes; apart from hunger and pain, these fearful phenomena have an external source. Predators seem to lurk at every corner and behind any bush: any sound or event may signify danger and constant vigilance is 
paramount to survival. In the human mind, any effect must have been caused by an event that preceded it. The concept of cause and effect comingled into precedent and consequent: Post hoc ergo propter hoc; after this, therefore because of this. This mode of thought is the essence of superstition which continues to be the 'default mode' of human reasoning to this day; but occasionally rationality overrides it. We shall see the significance of this type of cognitive dissonance in relation to the placebo magic as we unfold the evolution of human cognitive processes.

In all social animals, ants, bees, termites and social mammals, co-operation is the 'sine qua non' of predatory hunting. Tactical co-operation has been documented in lions, hyenas, chimpanzees as well as humans, and in all these cases there is an alpha-male that leads the pack.

There is some evidence that in the upper paleolithic era, Homo sapiens hunting groups were formed of a family or a clan of related individuals led by their leader, probably the clan chief, who wielded authority and organized the cooperative assault and so obedience to this authority must have been essential for success. At the same time humans were vulnerable to attack by predators as well as feeling powerless in the face of environmental forces; nature was imbued with malevolent spirits which needed propitiation and appeasement.

The three major factors so far seem to be obedience to authority, co-operation within groups and a syntactical language to communicate with each other. Perhaps it is in this upper paleolithic period that shamanism gradually appeared. The shaman was separate from the group and the clan leader and probably had certain characteristics and performed certain rituals which gave him the authority to gain the trust and reverence of the clan. He became the medium through whom the populace could attempt to appease the malevolent forces of nature as well as to seek amelioration of their physical maladies.

Shamans seem to have appeared fairly recently in human social evolution in the upper paleolithic; perhaps together with the advent of suggestibility and the belief in supernatural phenomena.

\section{Imitation and Suggestibility in Human Infants}

In recent years, a neuronal system has been discovered which operates in humans and non-human primates in the neonatal period, as well as later in life, called the 'mirror neuron system. This system allows the neonate to imitate previously unseen behaviors by their mothers and thus engage in social interaction with others. This mirroring mechanism seems to be embedded in the parietalpremotor neuronal circuits. It is postulated that this innate mechanism positively correlates with later social, cognitive and motor processes of behavior. ${ }^{20}$ Recent studies have elucidated the suggestibility of children of preschool age once they have acquired verbal communication skills and how they succumb to suggestions regarding emotional and participatory events. ${ }^{21}$ This process underlies the longlasting effects of acquired learning and the influence of social pressures at this early stage of mental development and indelible memories and cognitive impressions formed at this young age.

\section{Genetics}

Since the discovery of human accelerated regions (HARs) in 2006, new light has been shed on specific human genetics and the role that these HARs might play in evolutionary significant behavioral traits peculiar to Homo sapiens.

HARs are segments of the human genome that have been conserved throughout vertebrate evolution but are strikingly different in humans, and are "differentially more expressed in higher-order cognitive networks in humans compared to chimpanzees and macaques and are involved in synapse and dendritic formation."22

The sequence variations in HARs are single nucleotide substitutions in highly conservative regions of noncoding genome which likely serve regulatory functions and HAR1s could be responsible for traits specific to the developments of certain human brain regions, including the frontal cortex and do not seem to be present in archaic hominins. $^{23}$

\section{The Default Mode Network}

The default mode network is a key cognitive human brain network mainly composed of the medial prefrontal cortex, posterior cingulate cortex and the angular gyrus.

The rapid evolutionary expansion of cognitive networks in the human brain seems to have run parallel with the high expression of the human-accelerated genetic regions (HARs) and are involved in cognition, intelligence, sociability, regulation of fear and anxiety as well as rewardbased decision making. ${ }^{22,24}$

The medial prefrontal cortex has been shown to play a key role in social understanding of others, emotional perception and empathy which play a crucial role in human social cognition. Perceiving and interpreting other people's emotional states is one of the most important steps during social interactions. ${ }^{25}$

\section{Summary}

In this article, we documented the factual existence of the placebo effect through experimental and clinical trials and showed that they exert hormonal and neuronal activity similar to an effective medication which the patient has experienced previously. We also suggested several possible mechanisms for the placebo effect including suggestibility, conditioning, obedience to authority, healer-patient relationship, co-operation within groups and the expectation to be healed. We documented imitation in infants through the mirror neuron system and the existence of suggestibility from an early age.

There is evidence of human social groups co-operating during hunting and the stratification of society in a hierarchical structure, perhaps demonstrated by the grave goods interred with the dead during the upper paleolithic era. These practices are peculiar to Homo sapiens and its 
closest relative, Homo neanderthalensis but have not been demonstrated in other Homo species prior to the upper paleolithic era.

HARs and in particular the HAR1 groups which are functional in neural development, show evidence of positive selection in human evolution and are not shared with archaic hominins but are specific to modern humans. There is recent evidence suggesting that both mental and physical health is influenced by neural systems that regulate both somatic physiology and high-level cognition. These neural systems include the ventromedial prefrontal cortex and the related default mode network which control behavior and peripheral physiology including autonomic, neuroendocrine and immune functions and guide learning from experience. ${ }^{26}$ The question that has remained is the advantage that such mechanisms might bestow upon the recipient so that it may be selected for its survival value during human evolution.

\section{Conclusion}

It is possible that both co-operation and obedience increase the cohesion of individuals within the social groups thus conferring a survival advantage for the species. Fear of illness and death are formidable emotions which require a means of appeasement. The expectation to be healed is an emotionally driven reward seeking behavior based on belief which has an obvious survival value. The evolutionary development of the brain's default mode network in Homo sapiens is an obvious system to operate the expectation of healing and thus the placebo effect.

We therefore suggest that the placebo magic is a result of an emergent phenomenon from the combination of several of the mechanisms mentioned above, some of which have been exapted for increased survival of the species.

\section{References}

1. Frisaldi E, Shaibani A, Benedetti F. Understanding the mechanisms of placebo and nocebo effects. Swiss Med Wkly. 2020;150:w20340. doi: 10.4414/smw.2020.20340.

2. Colloca L, Barsky AJ. Placebo and nocebo effects. N Engl J Med. 2020;382(6):554-61. doi: 10.1056/NEJMra1907805.

3. Enck P, Klosterhalfen S. Placebos and the placebo effect in drug trials. Handb Exp Pharmacol. 2019;260:399-431. doi: 10.1007/164_2019_269.

4. Schedlowski M, Enck P, Rief W, Bingel U. Neuro-biobehavioral mechanisms of placebo and nocebo responses: implications for clinical trials and clinical practice. Pharmacol Rev. 2015;67(3):697-730. doi: 10.1124/ pr.114.009423.

5. Kaptchuk TJ. Placebo studies and ritual theory: a comparative analysis of Navajo, acupuncture and biomedical healing. Philos Trans R Soc Lond B Biol Sci. 2011;366(1572):1849-58. doi: 10.1098/rstb.2010.0385.

6. Kong J, Gollub RL, Rosman IS, Webb JM, Vangel MG, Kirsch I, et al. Brain activity associated with expectancyenhanced placebo analgesia as measured by functional magnetic resonance imaging. J Neurosci. 2006;26(2):381-8. doi: 10.1523/jneurosci.3556-05.2006.

7. Zubieta JK, Bueller JA, Jackson LR, Scott DJ, Xu Y, Koeppe RA, et al. Placebo effects mediated by endogenous opioid activity on mu-opioid receptors. J Neurosci. 2005;25(34):7754-62. doi: 10.1523/jneurosci.0439-05.2005.

8. Benedetti F, Colloca L, Torre E, Lanotte M, Melcarne A, Pesare M, et al. Placebo-responsive Parkinson patients show decreased activity in single neurons of subthalamic nucleus. Nat Neurosci. 2004;7(6):587-8. doi: 10.1038/nn1250.

9. Milgram S. Obedience to Authority: An Experimental View. New York: Harper \& Row; 1974.

10. Pacheco-López G, Engler H, Niemi MB, Schedlowski M. Expectations and associations that heal: immunomodulatory placebo effects and its neurobiology. Brain Behav Immun. 2006;20(5):430-46. doi: 10.1016/j.bbi.2006.05.003.

11. Enck P, Benedetti F, Schedlowski M. New insights into the placebo and nocebo responses. Neuron. 2008;59(2):195206. doi: 10.1016/j.neuron.2008.06.030.

12. Nayernouri T. Homeopathy, ritual and magic. Arch Iran Med. 2018;20(11):718-22.

13. Kaptchuk TJ. The placebo effect in alternative medicine: can the performance of a healing ritual have clinical significance? Ann Intern Med. 2002;136(11):817-25. doi: 10.7326/0003-4819-136-11-200206040-00011.

14. Silberman S. Placebo effects and science journalism at the mind/body boundary. J Mind-Body Regulation. 2011;1(2):44-52.

15. White R. Visual thinking in the ice age. Sci Am. 1989;261(1):92-9.

16. Dobrovolskaya M, Richards MP, Trinkaus E. Direct radiocarbon dates for the Mid Upper Paleolithic (eastern Gravettian) burials from Sunghir, Russia. Bull Mem Soc Anthropol Paris. 2012;24(1):96-102. doi: 10.1007/s13219011-0044-4.

17. Dale Guthrie R. The Nature of Paleolithic Art. Chicago: University of Chicago Press; 2006.

18. Mithen S. The Prehistory of the Mind. Great Britain: Thames and Hudson Ltd; 1996.

19. Heyes C. New thinking: the evolution of human cognition. Philos Trans R Soc Lond B Biol Sci. 2012;367(1599):2091-6. doi: 10.1098/rstb.2012.0111.

20. Simpson EA, Murray L, Paukner A, Ferrari PF. The mirror neuron system as revealed through neonatal imitation: presence from birth, predictive power and evidence of plasticity. Philos Trans R Soc Lond B Biol Sci. 2014;369(1644):20130289. doi: 10.1098/rstb.2013.0289.

21. Bruck M, Ceci SJ. The suggestibility of children's memory. Annu Rev Psychol. 1999;50:419-39. doi: 10.1146/annurev. psych.50.1.419.

22. Wei Y, de Lange SC, Scholtens LH, Watanabe K, Ardesch DJ, Jansen PR, et al. Genetic mapping and evolutionary analysis of human-expanded cognitive networks. Nat Commun. 2019;10(1):4839. doi: 10.1038/s41467-01912764-8.

23. Levchenko A, Kanapin A, Samsonova A, Gainetdinov RR. Human accelerated regions and other human-specific sequence variations in the context of evolution and their relevance for brain development. Genome Biol Evol. 2018;10(1):166-88. doi: 10.1093/gbe/evx240.

24. Gordon EM, Laumann TO, Marek S, Raut RV, Gratton C, Newbold DJ, et al. Default-mode network streams for coupling to language and control systems. Proc Natl 
Acad Sci U S A. 2020;117(29):17308-19. doi: 10.1073/ pnas.2005238117.

25. Li W, Mai X, Liu C. The default mode network and social understanding of others: what do brain connectivity studies tell us. Front Hum Neurosci. 2014;8:74. doi: 10.3389/ fnhum.2014.00074.

26. Koban L, Gianaros PJ, Kober H, Wager TD. The self in context: brain systems linking mental and physical health. Nat Rev Neurosci. 2021;22(5):309-22. doi: 10.1038/s41583021-00446-8.

Received: June 15, 2021, Accepted: June 28, 2021, ePublished: July 1, 2021

Cite this article as: Nayernouri T. The expectant brain and the placebo magic does it have a survival value?. Arch Iran Med. 2021;24(7):585-590. doi: 10.34172/aim.2021.83

(c) (1) 2021 The Author(s). This is an open-access article distributed under the terms of the Creative Commons Attribution License (http://creativecommons. org/licenses/by/4.0), which permits unrestricted use, distribution, and reproduction in any medium, provided the original work is properly cited. 